\title{
An information ecology approach to science-policy integration in adaptive management of social-ecological systems
}

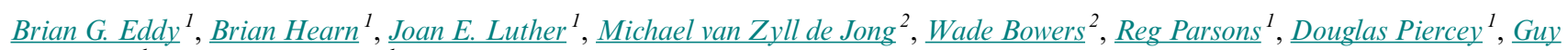 \\ Strickland $^{1}$ and Barry Wheeler ${ }^{1}$
}

\begin{abstract}
Adaptive management of social-ecological systems requires integration and collaboration among scientists, policy makers, practitioners, and stakeholders across multiple disciplines and organizations. Challenges associated with such integration have been attributed to gaps between how human systems are organized and how ecosystems function. To address this gap, we explore the application of information ecology as a theoretical basis for integrating human systems and natural systems. First, we provide an overview of information ecology with reference to its relationship with information theory and how we define "information." Principles governing whole-part relationships, i.e., holons and holarchies, are then used to develop a general information flow model for evolutionary, complex adaptive systems. This general model is then applied to examine a number of issues related to science-policy integration and in the development of a reference framework for practical application in adaptive management. A number of additional considerations for practical use of the framework are also discussed.
\end{abstract}

Key Words: adaptive management; ecosystems-based management; holons; information ecology; information theory; science-policy integration

\section{INTRODUCTION}

In recent years, significant attention has been given to challenges related to science and policy integration for organizations tasked with dealing with complex social-ecological issues (Rykiel 2002, Hearn et al. 2008, Pollard et al. 2008, Baehre et al. 2011). These challenges are multifaceted in that they require integration and collaboration among multiple organizations operating across many sectors and jurisdictions, with mandates that are increasingly expanding into a plethora of activities related to environmental assessment, regional land-use planning, sustainable resource management, environmental protection, and regional economic development, to name a few (Baskerville 1997, Harris 2002, Gibson 2007, Mitchell and Shrubsole 2007, Cantin 2010, Waldick 2010). This range of activities has led to the development of such a diversity of organizational frameworks that many are beginning to question whether there can be any one overarching construct for addressing such a wide range of issues simultaneously (Christensen et al. 1996, Grumbine 1997, Yaffee 1999, Dovers and Price 2007, Price et al. 2009, Layzer 2010, McAfee et al. 2010). Part of the challenge is that many of these activities have come to mean the same thing (Slocombe and Hanna 2007), and this has led to the development of frameworks that encompass multiple issues under holistic constructs such as adaptive management (AM; Holling 1978), ecosystems-based management (EBM; Kappel et al. 2006), or "place-based" strategies that focus on helping communities and regions adapt to multiple processes simultaneously (Rammel et al. 2007, Harcourt 2010, O’Brien 2012).

Although holistic concepts such as AM and EBM are pointing us in new directions, questions still remain with respect to how we may be better organized within such an approach. Some researchers suggest that the solution lies not so much in finding universal agreement on overarching management frameworks, but rather, it is "how we think about integration" that will bear on the success of its implementation (Dovers and Price 2007,
Slocombe and Hanna 2007). Addressing complex socialecological issues also requires the relationship between science and policy to be better defined. At issue is a question of "organization," particularly in terms of how we as human beings need to find a more efficient and effective means for addressing complex social-ecological issues.

One approach is to develop a new "mental model" (Jones et al. 2011) that addresses the significant gaps between how human systems are organized and how ecosystems function (Grumbine 1997, Yaffee 1999). Arguably, organizational frameworks used during the modern era reflect mental models that are more mechanistic than organic in nature, and new models are needed that focus "less on concepts of the industrial age and more on organizational theories relevant to an information age" (Yaffee 1999:718). Complex adaptive systems theory provides a starting point, where human systems are viewed as interdependent and coevolutionary with natural systems (Patten et al. 2002, Able and Stepp 2003, Szaro et al. 2005, Kappel et al. 2006, Rammel et al. 2007, Gunderson 2010).

Following this approach will therefore require a more explicit incorporation of ecological principles in management and organizational frameworks to enable organizations to be more reflexive in responding to complex social-ecological problems (Biggs et al. 2010, Folke et al. 2010, O'Brien 2012). This requires going beyond simply attempting to adjust or adapt existing industrial-era management structures to address more complex dynamics of emerging social-ecological problems. Whereas industrial-era models are based on modes of production rooted in material transformation and flow, information-era models need to focus on information transformation and flow. However, the role of "information" for such transformation has been given little or no attention in this regard, even though it is a subject that has been explored at great length in evolutionary, complex adaptive systems research (e.g., see Wicken 1987, Küppers 1990, Schneider 
and Kay 1994, Stonier 1997, Coren 1998, Kay 2000, Salthe 2003, Hogeweg 2007). Whereas much of this work builds on Shannon and Weaver's (1949) "Information Theory," its focus on mathematical and quantitative aspects of information transmission and communication is limited in addressing more ephemeral, qualitative dimensions of information processes in dynamic human organizational environments.

To address these aspects, we examine the emerging field of "information ecology" as a means for integrating multiple aspects of information flow as it relates to organizational structural and functional configurations for science-policy integration in general and AM in particular. We do this by synthesizing theoretical elements from a number of areas to illustrate how information is collected, processed, transformed, transmitted, and used among multiple disciplines at different levels within organizations from primary scientific research to policy analysis and decision making.

We provide a brief overview of information ecology to set the context of its scope of application, to examine how it contrasts with information theory, and to highlight a number of gaps that need to be addressed to enable its application in science-policy integration and AM. This includes providing some clarification on what is meant by the term "information" and why there are many contexts and definitions for its use. We use principles derived from the concept of holons and holarchical systems to describe intrinsic structural properties related to how information functions in evolutionary, complex adaptive systems.

We use these general principles in the development of a general model and reference framework to guide practical application, including an examination of a number of issues related to sciencepolicy integration. Insights provided by this analysis are then used to elaborate more specifically how it can be applied in an AM context. We close with a discussion of a number of salient issues that need to be kept in mind when applying this approach in practical settings, along with some additional theoretical speculations and suggestions for further research.

\section{INFORMATION ECOLOGY}

\section{Overview}

The term "information ecology" is used in many areas of research that include studies of animal behavior and human psychology (Dall et al. 2005, Fiedler et al. 2007), comparative studies of human ecosystems and natural ecosystems (Erymonin 1998, Stepp et al. 2003), and within the human realm of information systems development, business processes, organizational theory, politics, and culture (Davenport 1997, Rasmussen 1999, Nardi and O'Day 2000, Malhotra 2002, Bekkers and Homburg 2005). Although there is not yet a core body of knowledge or theory associated with the field, it is reasonable to categorize two general areas where the term is applied: (1) information environments within human organizations and (2) information environments that involve the interaction between human and natural systems.

The first area focuses specifically on information technology and management (IT/IM) with particular attention to political and cultural aspects of information use within human organizations. In this context, ecology is used as a metaphor on the rationale that processes that affect information flow and use in human organizations exhibit characteristics similar to processes observed in natural systems. Davenport (1997:28) contrasts information ecology with conventional approaches to IT/IM in the following way:

Information ecology includes a much richer set of tools
than that employed to date by information engineers and
architects. Information ecologists can mobilize not only
architectural designs and IT but also information
strategy, politics, behaviour, support staff, and work
processes to produce better information environments...
They rely on the disciplines of biology, sociology,
psychology, economics, political science, and business
strategy - to frame their approach to information use.

In a similar vein, Nardi and O'Day (2000) emphasize qualitative and ephemeral dimensions that tend to be missed by technologycentric approaches to IT/IM. For example, they question how the notion of an "information community" is treated in mainstream IT/IM as a homogenous environment with definable characteristics. They offer an alternative perspective that views human information environments as more open, dynamic, and nonlinear, with characteristics that are continuously changing, and for which there can be multiple and overlapping communities. A number of ecological concepts they use to characterize human information environments include the metaphor of a keystone species to refer to specific individuals in an organization that are deemed critical for information flow and connectivity, as well as locality, context, and habitat.

The second area to which definitions have been proposed are those that include the study of information processes in both the human domain and the natural world, with particular attention given to the role of information in the interaction between the two. In this context, Stepp (1999:41) defines information ecology as:

... the study of the relationship of environmental information (at least physical, biological, social and cultural environments) to all that comprises collective and individual processes of knowing and decision making (ideology, values, expectations, beliefs, symbolism).

The idea of extending the functional role of information in natural systems to the study of human systems is further advocated by Eryomin (1998:241), who offers the following perspective:
Information ecology is a science which studies the laws governing the influence of information summary on the formation and functioning of bio-systems, including that of individuals, human communities and humanity in general and on the health and psychological, physical and social well-being of the human being; and which undertakes to develop methodologies to improve the information environment.

Although there are differences in perspective, it is evident from these descriptions that the intent is to use information ecology as a framework to provide a more open, dynamic, and ecological context for studying how information processes operate in both human and natural environments. What is missing in the literature, however, is a general model that can provide a more explicit link between how information functions in natural systems and human systems in an adaptive, evolutionary context. 
We propose an initial conceptual model to fill this gap. In pursuit of such a model, it is first necessary to examine what is meant by the term "information."

\section{Defining information}

"Information" is one of the most widely used words in modern times, and there can be many differences in meaning depending on the context in which it is used (Mingers 1997, Eddy and Taylor 2005). Dictionaries typically provide several colloquial definitions that are often based on circular reasoning and that at times may even be contradictory (Stonier 1997). For example, defining information as "data that is transformed into knowledge" is counterintuitive to other definitions that regard "data" and "knowledge" as specific "types" of information. In a related context, information is commonly regarded as an intermediate level between data and knowledge, as typically seen in datainformation-knowledge-wisdom pyramids. Although such models have been widely adopted, a critical review reveals the origins of the concept to be without solid theoretical or empirical foundation (Rowley 2007). These apparent contradictions are now pervasive in everyday discourse to such an extent that the term is often simply taken for granted, and multiple connotative meanings take precedence over more technical denotative meanings. Proponents of information ecology take a pluralistic approach to accommodate these multiple, even contradictory, definitions of the term so that it is not confined, nor reduced to one particular form or domain. Differences in meaning relate not so much to a lack of agreement on what information is or is not, in a denotative sense, but more so on the dynamic nature and multiple contexts within which the term may be defined and used, in a connotative sense (Mingers 1997).

There are, however, a number of fundamental principles provided in information theory that may shed some light on why there are so many contexts for its meaning and use. We draw on principles originally developed by Shannon and Weaver (1949) and applied further in the study of evolutionary processes in biological and ecological systems that also draw from more recent developments in nonequilibrium thermodynamics (Wicken 1987, Küppers 1990, Schneider and Kay 1994, Coren 1998). According to this school of thought, information is regarded as a complement of entropy in self-organizing systems. Although entropy has historically been regarded as a direct measure of disorder in systems, it is now regarded as a measure of the number of possible pathways a system may take in terms of its organizational structure (Kay 2000). Although highly disordered systems have high entropy, not all systems with high entropy are disordered or chaotic. The distinction pertains to the amount of information present in a system, which is directly reflected in the level of complexity in its organizational configuration. Stated another way, ordered structural-functional configurations that emerge from the interaction of matter and energy in complex systems reflect the degree of information contained in the system as a result of such interactions.

This is illustrated with the help of Figure 1, which contrasts a random system with little or no organization (Fig. 1a) with a system that exhibits a higher degree of organization and structure (Fig. 1b). The organized system has lower entropy because of the formation of a structural configuration of constituent elements that reduces the number of possible pathways the system may
Fig. 1. Illustration of the concept of information as the complement of entropy: (a) a highly disordered system with high entropy and low information and (b) an ordered system with lower entropy and higher information.

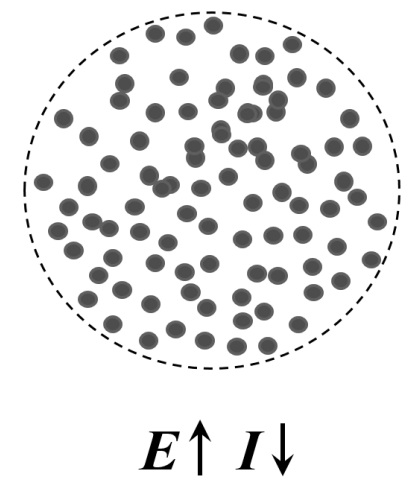

(a)

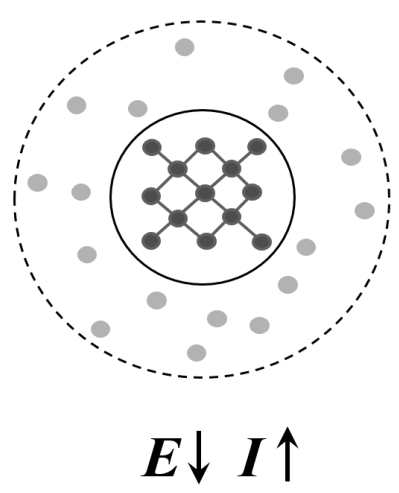

(b) take and, therefore, has more information. A planetary system, for example, has more information than the cloud of particles from which it formed. This approach regards information as the innate tendency for evolutionary, self-organizing systems elements to organize into some ordered formation, or "in formation." As Stonier (1997:14) postulates how "information is to organization, what mass is to matter, and heat is to energy," it follows that information be used as a definitive element in understanding organization, whether dealing with simple, complicated, complex, or chaotic systems.

Such a view provides a basis from which multiple meanings and contexts may be more fully appreciated. The degree of organization in a system is in part a function of a system's response to environmental conditions and highlights the intrinsic relationship between information "content" of a system, i.e., the organizational configuration, and the "context," i.e., environmental conditions, in which it formed. Because there are many types of systems to which this definition can apply, e.g., physical, biological, social, linguistic, technological, and representational, there can therefore be as many definitions or contexts for the use of the term as there are systems of interest.

It is also possible to examine how this approach to defining information may implicate how we define terms such as data, knowledge, or meaning and in which contexts such distinctions need to be made. Building on the work of Lindholm and Sarjakoski (1994) and Rasmussen (1999) in the fields of geomatics and information systems design, Eddy and Taylor (2005) define these terms generally as data being any raw sensory information that describes "what there is," knowledge as information that describes "how things work," and meaning as information applied in terms of "what it means/what to do" in a given circumstance or decision context. Data used in a knowledge context are given a higher degree of organization through analysis and interpretation, and therefore, it can be deduced that knowledge has more information than data. It follows that knowledge is structurally dependent on data as a primary input, and all forms 
of knowledge have meaning in some context (Eddy et al. 2006). It is therefore more accurate to say that all information contains some combination of data, knowledge, and meaning, whether explicit or implied, and it is important to consider how these aspects function simultaneously as a nested relationship.

The intrinsic structural-functional dependencies in the progression from data to knowledge to meaning can be equated with three levels of semiotic relations identified by Küppers (1990) as the following: (1) syntactic, (2) semantic, and (3) pragmatic. The syntactic pertains to the ordering of primary elements in a message or code, e.g., letters, numbers, and symbols, or "data"; the semantic pertains to many possible arrangements that can be made from primary elements, such as words that comprise meaningful sentences or different knowledge statements inferred from data. Whereas the syntactic and semantic combine to make up the "content" of a message, the pragmatic aspect pertains to the usefulness of the message in a particular context, i.e., "meaning." When these structural-functional dependencies are viewed in terms of levels of semiotic relations, as Küppers (1990) makes explicit, some general principles can be used to provide a means for thinking differently about how information can be used as a basis for integration. We turn to some general principles derived from the theory of holons and holarchies that offer some additional insights on nested dependencies.

Holons, holarchies, and information structure

The concept of a holon was first developed by Koestler (1967) as a means to accommodate both reductionistic and holistic dimensions of complex systems. The term literally means "wholepart" and, more specifically, refers to the relational dependencies among wholes and parts in complex systems. Koestler developed a set of general principles that describe how structural-functional dependencies are governed by holonic relations. Some of these principles have been incorporated in various ways in hierarchy theory (e.g., see Allen and Starr 1982, Salthe 1985, and O'Neill 1989); however, for simplicity, several more concisely stated "holonic tenets" described by Esbjörn-Hargens and Zimmerman (2009:85) will suffice for this analysis. In contrast to spatiotemporal properties used in hierarchy theory, such as smaller/larger or faster/slower levels in natural systems, the holonic tenets focus on structural-functional dependencies between holonic levels in terms of higher and lower relationships in multilevel "holarchical" systems, which can be physical, biological, ecological, symbolic/linguistic, or any other type of structurally ordered system. The following four tenets are used to describe a few of the core principles:

1. Each holonic level transcends and includes holons on lower levels.

2. Lower level holons set the possibilities for the higher level holons; and higher level holons set the probabilities (constraints) on the lower levels.

3. Destroy holons on any particular level, and all the levels above it are destroyed, but none of the levels below it.

4. Each level in a holarchy produces greater depth and less span.

Two simple holarchical systems are used for illustration. The first is a physical system pertaining to how molecules form from atoms, and the second is a symbolic system pertaining to how words are composed of letters (Fig. 2). In both systems, higher levels, i.e., molecules or words, are composed of the holons that make up the lower levels, i.e., atoms or letters. Holons exist on both levels; they are, in part, wholes unto themselves, i.e., atoms or letters, yet simultaneously parts of another whole, i.e., molecules or words. Higher level holons in each example may subsequently become parts of larger wholes, such as organisms or sentences, respectively. Koestler (1967) referred to this as a "Janus-effect," meaning that all holons have two faces, one of wholeness unto itself and the other as a part of another whole or broader system. A holarchy can contain any number of levels of holonic relationships, depending on the complexity and holonic depth of a given system.

Fig. 2. Graphical illustration of holonic relations and information structure.

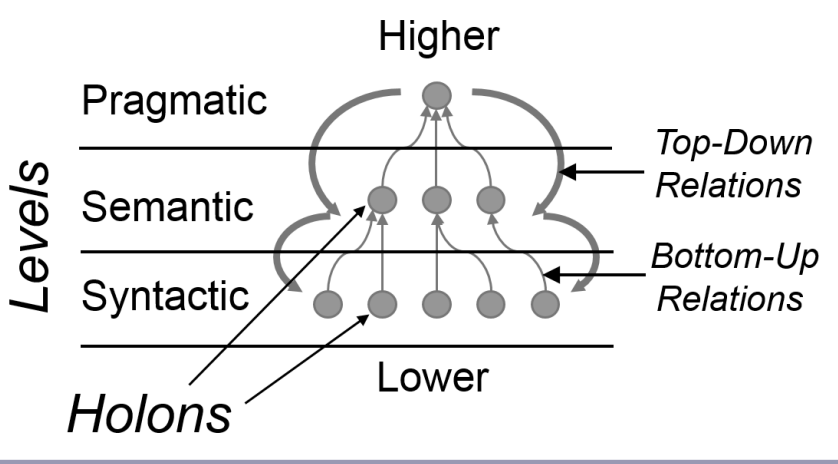

The first tenet emphasizes how each level "transcends and includes" lower level holons. This principle focuses attention on the nested dependencies present among multiple levels of a system, in contrast to focusing on particular levels in the exclusion of other levels. The pertinent notion is the explicit recognition that higher levels do not operate in a detached fashion from their constituent parts, as the term transcendence sometimes implies; higher level holons not only transcend but also include lower level holons, and it is the lower level holons that make the existence of the higher level holons possible. The second tenet builds on this logic in stating how lower level holons set the possibilities for higher level holons, a bottom-up relationship. For example, the types of molecules or words that form in a particular context depend first on the types of atoms or letters that are available. As these levels in a system emerge and a holonic level comes into formation, it does so partly as a result of setting behavioral constraints on the lower level holons, which is stated as the higher sets the probabilities of the lower, a top-down relationship. For this reason, it is said that levels in a holarchical system "emerge" and "coevolve" through both bottom-up and top-down interaction among levels.

Although the structural and functional dependencies among levels is nonlinear and dynamic, there is a "not vice versa" principle that is intrinsic in the holonic structure of ordered systems. For example, words are made of letters and molecules are made of atoms, not vice versa. The properties that define a particular holonic level, e.g., a molecule of water, are different from those of the lower level holons, hydrogen and oxygen, but 
are derived from a combination of their properties. Ordered systems are therefore vulnerable to cascading effects in that if the integrity of holons on a particular level is destroyed or negatively affected, then so too will be the integrity of the holons on the higher levels, but not necessarily to levels lower than those affected (tenet 3).

How one applies the holonic tenets to analyses of complex systems depends on the nature of the systems being studied. This is particularly relevant for the use of the fourth tenet, which specifies how with increasing levels there are fewer holons, stated as "greater depth, less span." In a strict hierarchical sense, depth refers to the number of holonic levels in a system, and span refers to the number of holons on a particular level. For example, a word is composed of one or more letters, as is a molecule of one or more atoms, not vice versa. Although this general principle holds for singular cases in closed, bounded systems, there are many possible permutations that can be made of the same primary elements in open, unbounded systems. Esbjörn-Hargens and Zimmerman (2009) emphasize this distinction by differentiating individual holons, i.e., closed, physically bounded holons, such as a tree or a person, from social holons, i.e., open, ephemeral holons, such as a forest or a community. In their framework, the term "social" is not confined to the interaction among humans only but is extended to describe the interactions that occur among any type of individual physical, biological, or linguistic holons in space and time. Although individual holons are hierarchically structured, the many possible permutations that can emerge in complex systems can result in a variety of heterarchical arrangements (Fig. 3). Both human and natural systems involve different types of individual holons functioning in some form of collective behavior as social holons, and it is the interaction between these hierarchical and heterarchical arrangements across different spatiotemporal scales that contributes to the complexity of complex systems. It is for this reason that the term "holarchy" is preferred over the conventional notion of hierarchy, whereby a holarchy is a multileveled system composed of both hierarchical and heterarchical arrangements that are structured through both bottom-up and top-down relational dependencies and interaction: holarchy $=$ hierarchy + heterarchy.

In essence, the holonic tenets provide a set of principles by which intrinsic structural-functional configurations of complex systems

Fig. 3. Graphical illustration of multiple hierarchical arrangements comprising a heterarchy.

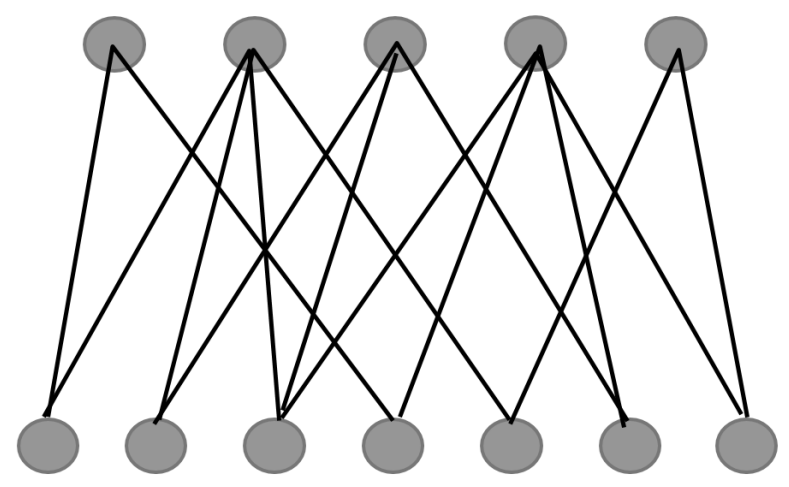

can be analyzed and are therefore inherent to the general definition of information and, consequently, may be applied to a variety of system contexts. For the purpose of applying these ideas to science-policy integration in AM, we provide a summary of this theoretical overview in the form of a general model.

\section{Summary and general model}

The main intent in applying information ecology for AM is to draw attention to the role of information structure and function in both human and natural systems as they coevolve over time. Adopting theoretical principles that are common to both human and natural systems provides a foundation for thinking differently about how to better align human systems with natural systems and, consequently, develop more coherent and comprehensive approaches toward integration across disciplines and organizations. The theoretical principles we describe are summarized subsequently with the help of the schematic in Figure 4, which is based on a model of autopoietic (self-organizing) systems (Maturana and Varela 1980) and depicts how information flows in an evolutionary, adaptive system context, using a species and its environment as a general example.

Fig. 4. General reference model of information structure and flow in evolutionary, adaptive systems, e.g., a species and its environment.

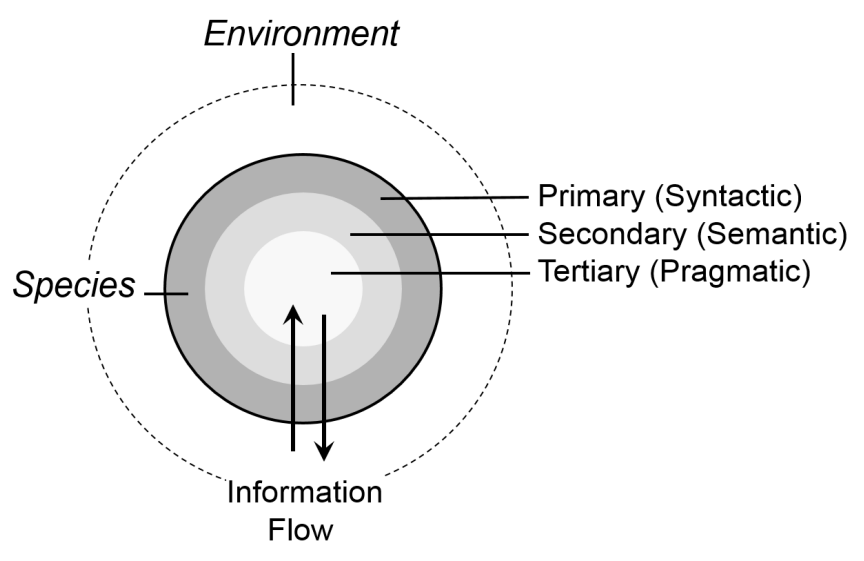

- On a fundamental level, information pertains to the degree of organization in a system, which occurs partly as a result of how a system, i.e., an organism, species, or population, responds to changes in environmental conditions.

- Self-organizing (autopoietic) systems evolve and adapt by processing information through three successive levels: (1) syntactic, (2) semantic, and (3) pragmatic. To simplify terminology, these are subsequently referred to as primary, secondary, and tertiary levels.

- The primary, secondary, and tertiary levels are successively structured in a holarchical manner and follow the general principles set out in the holonic tenets.

- Individual ecological entities, i.e., individual holons, such as cells, animals, or human beings, are hierarchically 
structured; whereas the interaction among individual ecological entities, i.e., social holons, such as populations, gives rise to heterarchical configurations.

- Holonic and holarchical levels "emerge" and "coevolve" through both bottom-up and top-down interactions. However, a "not vice versa" principle requires fundamental dependencies of lower levels on higher levels, and higher levels provide new systemic contexts for lower level organization.

- Information ecology involves the study of information both within and between human and natural systems in this context. It deals with all aspects of information production, flow, and use, as well as both quantitative and qualitative aspects, and therefore provides a basis for examining the role of different types of information for a variety of purposes.

\section{REFERENCE FRAMEWORK}

\section{Context and scale}

The general principles outlined with the model presented in Figure 4 are applicable to many types of systems that operate across a wide range of scales, from individual micro-organisms and their microenvironments to large populations and their corresponding macroenvironments. Consideration can be given to multiple contexts in relation to ecological processes that operate across diverse spatial and temporal scales (Eddy 2005, Mitchel and Shrubsole 2007, Jørstad and Skogen 2010), whereby specific structural-functional configurations of each level differ in relation to the scale and nature of the system under consideration. For example, on the scale of an individual animal species, the three levels pertain to its (1) sensory-physiological capacity, (2) neurological-memory capacity, and (3) instinctual-behavioral capacity, respectively. For a species to adapt to changing environmental conditions, it must have the capacity to both absorb information from its environment and process it internally through all three levels to enable a proper adaptive response. As a general principle, failure to accomplish this process will result in the inability of the species to evolve and adapt.

We examine how this model can be applied in the development of a general reference framework for application on the scale of the interaction between human systems and natural systems. In this context, the three levels pertain more broadly to the following: (1) the human capacity to gather factual information about ourselves and the natural environment, (2) the capacity to integrate information and identify problems and potential solutions, and (3) the capacity to decide and take an appropriate course of action. For the purpose of developing a general reference framework, we proceed in two steps. The first step involves looking at how information flow between levels corresponds with issues related to science-policy integration. The second step examines what is needed within each level to be applicable in an iterative, learning-based AM context.

\section{Science, policy, and decision support}

One of the more salient issues related to integration in AM is the continuing debate with respect to the role of science in policy and decision making. Ensuring that policy and decision making are science or evidence based, or making science more policy relevant, requires some degree of integration between the two domains. Figure 5 presents three ways of visualizing challenges associated with this integration. The first (Fig. 5a) suggests the relationship be viewed in terms of a "supply and demand" model (e.g., see Sarewitz and Pielke 2007), whereas the second (Fig. 5b) suggests the interface is more of a "complex interaction" than simply a unilateral or bilateral flow of information from one domain to the other (e.g., see Jørstad and Skogen 2010).

Fig. 5. Three ways of characterizing the current state of science-policy integration in adaptive management: (a) separate cultural domains operating according to a "supply-demand" approach, (b) a direct integration of the two domains, and (c) a three-tiered framework involving a level of decision support.

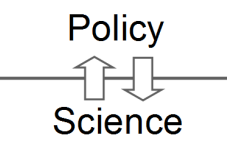

(a)

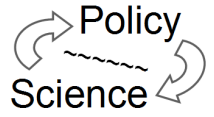

(b)

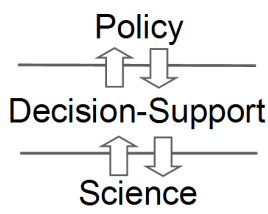

(c)
Efforts to foster better integration by focusing on improving communication and knowledge exchange confront a number of challenges related to cultural differences between the two domains. The cultures of science and policy have been variously characterized as having contrasting operational constraints and time horizons, different languages and audiences, different methods of accountability, and different political drivers (Holling 1998, Bradshaw and Borchers 2000, Saner 2007). Such characteristics are similar to what Davenport (1997) uses to differentiate "information environments" in organizations. Analogous with the ecological concept of a habitat, the respective cultures of both science and policy evolved over long periods of time and acquired their cultural characteristics for important functional reasons. Although this presents challenges with communication and information exchange (Fig. 5a), there is also evidence that suggests that the direct mixing of the two (Fig. 5b) contributes to even greater institutional inefficiencies (Rykiel 2002, Baker and Bowker 2007).

In the interest of maintaining cultural and functional integrity of both domains, a number of authors suggest that a level of mediation between the two is required for effective and efficient integration (Davenport 1997, Nardi and O'Day 2000, Opdam et al. 2001, Stevens et al. 2007). This is illustrated in Figure $5 \mathrm{c}$ as a three-tiered model with the insertion of a level of decision support. In essence, this approach combines the two scenarios depicted in Figure 5a, b where the integration of science and policy is facilitated by a level of decision support while preserving the cultures of the two domains. The type of expertise required on this level includes both applied scientists and policy analysts who understand the intricate nature of scientific information, the circumstances, and the context of the decision-making environment they are supporting and, with the help of knowledge exchange specialists, are well practiced in integrating and translating complex information more effectively under constraints of limited time and resources (Christensen et al. 1996, Opdam et al. 2001, Rykiel 2002, Stevens et al. 2007). 
The type of integrative science conducted in a secondary level, i.e., decision support, environment is markedly distinct from primary research in that its aim is to address particular policy issues. It usually does not engage in the collection of raw data as a priority activity, except in cases where critical data gaps need to be filled. The distinction among these levels has been characterized with a variety of terms such as analytical (primary) and integrative/ systemic (secondary) science (Holling 1998, Saner 1999); policydistal (primary) and policy-proximal (secondary) science (Jung 1999); and actionable (Roux et al. 2006) or regulatory science (Jørstad and Skogen 2010), to name a few. The three levels also appear in integration frameworks where specific roles are identified for "domain experts" (primary), a "core team" (secondary), and "all participants" (tertiary; e.g., see Fall et al. 2001, Sturtevant et al. 2007). Others note an important distinction between the secondary and tertiary levels in that the role of decision support is to be objectively "informative," whereas the tertiary level is primarily a "decisive" environment (Dovers and Price 2007, Rammel et al. 2007). The latter involves the formulation and implementation of decision outcomes, reflected in new or modified policies, laws, regulations, programs, and so forth, and is conducted in environments that may often be subject to sensitive political factors, e.g., public pressure, budgetary priorities, or other political issues.

The model presented in Figure 4 provides a basis to examine how these relationships between science and policy may be characterized from an information ecology perspective. What others observe as a problematic interface between science and policy can be attributed to the lack of a semantic interface between the syntactic role of science and the pragmatic challenges of policy and decision making. In this context, policy can be viewed as equivalent to the tertiary (pragmatic) level, and pure scientific research is viewed as equivalent to the primary (syntactic) level. Scientific information products, treated as independent factual elements, function as primary inputs that can be integrated and synthesized in a variety of ways to inform policy and decision making. This process is facilitated by the mediating function of decision support, which is equivalent with the secondary (semantic) level wherein a variety of alternative scenarios or propositions to specific problems need to be explored in a manner that is often iterative and participatory with both primary- and tertiary-level input. Examining science and policy integration from this perspective leads to a number of observations using the holonic tenets and the "not vice versa" principle:

- The integration of science in policy and decision making requires a three-tiered multilevel system of information processing and flow among primary, secondary, and tertiary levels that emerge and coevolve through both bottom-up and top-down dynamic interaction. Factual information (content) flows forward from primary to secondary to tertiary levels, and pragmatic information (context) provides feedback on lower levels. The secondary level provides a mediating interface to facilitate the appropriate use of factual (scientific) information in a variety of pragmatic, i.e., policy and decisionmaking, contexts.

- The quality of scientific information provided from the primary level, mediated through the secondary level, will influence the quality of decision making on the tertiary level, a bottom-up, supply relationship. Conversely, higher level policy issues, or pragmatic circumstances in general, may set the context for what scientific information is required or produced, a top-down, demand relationship. The transitory nature of policy and decision making is an "open context" that is in a state of continuous flux, which is why AM requires continuous iteration and learning.

- Whereas it is possible for scientific research to be conducted independent of any pragmatic or policy context, it is not without its own context in terms of its quest for pure knowledge. Decision making, however, is fundamentally dependent on the input of some form of objective information about the state of affairs it aims to address. The degree to which the information used is subject to a rigorous scientific process determines whether the decision-making environment is "science based."

- Ideally, scientific research, although not independent of its own context, should not be interfered with by political circumstances in the tertiary level, or it will risk sacrificing its need for scientific objectivity. This is not to say that all science is purely objective and all decision making is purely subjective, as both have their own forms and degrees of objectivity and subjectivity. What is important is that scientific inquiry operates without the influence of political ideologies in tertiary environments.

- Although science-based policy and decision making is a desired approach, it is important to recognize that scientific information is not always complete, nor without uncertainty or conflicting information. Uncertainties and information gaps may be the most critical factors that need to be considered by decision makers, who need to deal with them outside the realm of conventional scientific inquiry.

- It is intuitively apparent how the depth and span of information decreases as it flows from the lower levels to the higher levels. Large volumes of scientific data on the primary level need to be integrated and synthesized on the secondary level to produce concise summary products for use in tertiary-level environments. This is regarded as the hierarchical aspect of information flow.

- However, the same primary scientific data can be interpreted and processed in a variety of ways to either address a particular policy issue or to address multiple issues. This represents the heterarchical aspect of information flow (see Fig. 3), which can result in drawing different conclusions from the same primary data and, in some cases, lead to conflicting views in tertiary environments.

- Some of the implications for these relations mean that it is possible to discredit a particular decision by discrediting the scientific or factual information on which it is based, but not vice versa. Good-quality scientific information does not necessarily guarantee good-quality decisions, because other 
Fig. 6. General reference framework for science-policy integration and adaptive management based on principles of information ecology.

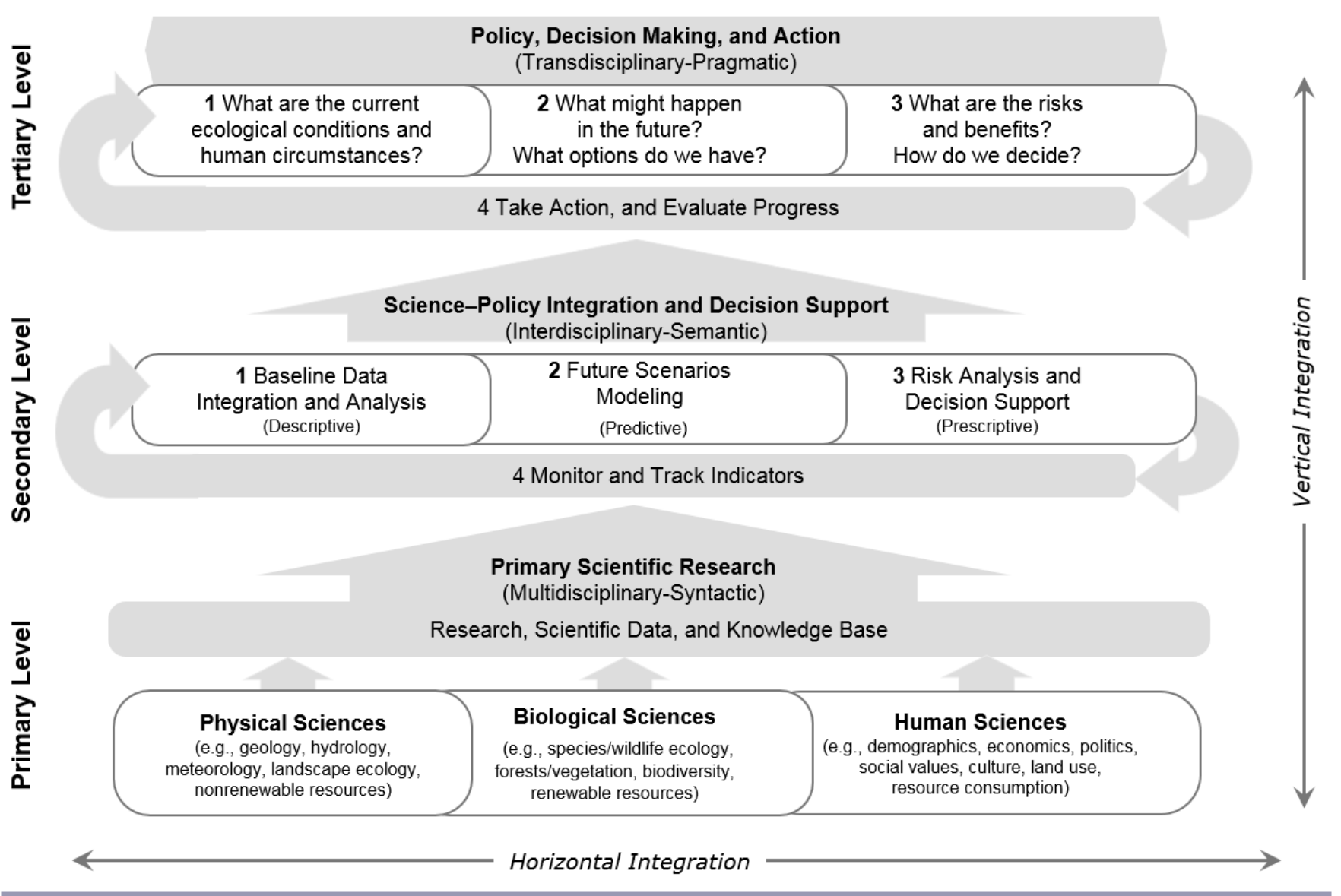

factors come into play on the secondary and tertiary levels. In simpler terms, it remains possible to make bad decisions with good scientific data, but it is less possible to make good decisions with bad scientific data.

\section{Application to adaptive management}

The management of human interaction with natural systems requires integration of multiple areas of the natural and social sciences to address complex social-ecological issues. Challenges associated with the complexity and highly unpredictable nature of this interaction are what some researchers refer to as "wicked problems" (Rykiel 2002, Pollard et al. 2008). As mentioned in the introduction, areas of focus cover a wide range of activities that come under various names, many of which have come to mean the same thing. The concept of AM (Holling 1978) provides a synoptic, yet practical frame of reference to address the complexities involved in these activities. EBM is one approach to $\mathrm{AM}$, and for the purpose of this analysis, we use the following definition provided by the Ecological Society of America:

... an integrated, science-based approach to the management of natural resources that aims to sustain the health, resilience and diversity of ecosystems while allowing for sustainable use by humans of the goods and services they provide [and which] necessarily incorporates biological, physical, and human components, including social and economic systems. Ecosystemsbased management's goals include learning how these biophysical and socioeconomic spheres interact, and finding institutional and scientific ways of managing multiple human activities within entire ecosystems (rather than arbitrary management units), based on this understanding of the linkages among activities and social and ecological system components. (Kappel et al. 2006)

Although this definition focuses on the management of natural resources, the context can apply more broadly to managing the interaction between human systems and natural systems in general. Figure 6 provides an information ecology-based reference framework that identifies key requirements for a comprehensive approach to AM by expanding on the three-tiered model presented in Figure $5 \mathrm{c}$. The three levels are identified as policy, decision making, and action, i.e., tertiary level; sciencepolicy integration and decision support, i.e., secondary level; and primary scientific research, i.e., primary level. Table 1 provides additional details of some general characteristics of the three levels as "information environments." Each level involves a series of components and processes required to fulfill the respective information-processing functions and for which two types of 
Table 1. General characteristics of primary, secondary, and tertiary information environments; modified after Eddy and Taylor (2005).

\begin{tabular}{|c|c|c|c|}
\hline & $\begin{array}{c}\text { Primary Level } \\
\text { (Multidisciplinary) }\end{array}$ & $\begin{array}{l}\text { Secondary Level } \\
\text { (Interdisciplinary) }\end{array}$ & $\begin{array}{c}\text { Tertiary Level } \\
\text { (Transdisciplinary) }\end{array}$ \\
\hline $\begin{array}{l}\text { Information } \\
\text { Environment }\end{array}$ & $\begin{array}{l}\text { Researchers working in specialized } \\
\text { disciplines with specific paradigms and } \\
\text { practices. Primarily multidisciplinary } \\
\text { with some interdisciplinary } \\
\text { collaboration on closely related topics. } \\
\text { Research activities are aimed at } \\
\text { discovering "how things work." }\end{array}$ & $\begin{array}{l}\text { Integrative, collaborative research teams } \\
\text { involving both scientists and policy } \\
\text { analysts addressing particular social- } \\
\text { ecological issues. Activities are driven by } \\
\text { pertinent social-ecological issues, and the } \\
\text { aim is to "analyze problems and suggest } \\
\text { possible solutions." }\end{array}$ & $\begin{array}{l}\text { Decision-making environments } \\
\text { involving the public, senior policy and } \\
\text { political leaders, and stakeholders. } \\
\text { Activities are driven by pressing } \\
\text { political issues where the aim is to } \\
\text { "decide what to do, and take action." }\end{array}$ \\
\hline Inputs & $\begin{array}{l}\text { Recorded measurements and } \\
\text { observations of the real world (primary } \\
\text { data); can be quantitative or qualitative; } \\
\text { includes previous research/knowledge } \\
\text { of particular subject matter. } \\
\text { Information is highly technical, using } \\
\text { discipline-specific language. }\end{array}$ & $\begin{array}{l}\text { Primary data and knowledge reprocessed } \\
\text { for inclusion in integrative analyses. } \\
\text { Problem descriptions; analyses of context } \\
\text { and circumstances. Information is both } \\
\text { technical and policy oriented; language is } \\
\text { generalized to ease communication and to } \\
\text { better understand complex issues. }\end{array}$ & $\begin{array}{l}\text { Summary decision-making information } \\
\text { products, easy to use, understand and } \\
\text { communicate among people with } \\
\text { diverse backgrounds and areas of } \\
\text { expertise. Technical jargon is minimized } \\
\text { where possible; plain language is the } \\
\text { norm. }\end{array}$ \\
\hline Processing & $\begin{array}{l}\text { Analysis, interpretation, and } \\
\text { development of theories and } \\
\text { explanations of particular subject } \\
\text { matter (physical, natural and social } \\
\text { sciences, and humanities). }\end{array}$ & $\begin{array}{l}\text { Integrated analysis and modeling of a } \\
\text { particular geographic region/ecosystem } \\
\text { using physical, biological, and human } \\
\text { dimensions. Historical and current } \\
\text { scenarios (descriptive), modeling future } \\
\text { scenarios (predictive), and integrated risk } \\
\text { analyses (prescriptive). }\end{array}$ & $\begin{array}{l}\text { Structured, semistructured, or ad hoc } \\
\text { processes for addressing particular } \\
\text { issues. Usually involves multiple } \\
\text { stakeholders, consultations, } \\
\text { presentations, education and the media. }\end{array}$ \\
\hline Outputs & $\begin{array}{l}\text { Specialized databases, published papers, } \\
\text { presentations, reports. Usually specific } \\
\text { to particular disciplines (e.g., hydrology, } \\
\text { forest ecology, economics, sociology). }\end{array}$ & $\begin{array}{l}\text { Integrated ecosystems databases, } \\
\text { integrated models, dynamic simulations, } \\
\text { risk/trade-off analyses for use in planning } \\
\text { and decision making. }\end{array}$ & $\begin{array}{l}\text { Plans, guidelines, status reports, } \\
\text { regulations, policies, laws, and other } \\
\text { forms of mass communication. Action } \\
\text { items and delegation of responsibilities. }\end{array}$ \\
\hline $\begin{array}{l}\text { Information } \\
\text { Technologies }\end{array}$ & $\begin{array}{l}\text { Often highly specialized, depending on } \\
\text { the discipline and nature of the data to } \\
\text { be collected. Usually requires } \\
\text { specialized training. }\end{array}$ & $\begin{array}{l}\text { Integrated analyses, simulation modeling, } \\
\text { and other advanced technologies (e.g., } \\
\text { expert systems, decision-support systems). }\end{array}$ & $\begin{array}{l}\text { Internet/web-based content and } \\
\text { applications; mass media/ } \\
\text { communications; multistakeholder } \\
\text { consultation support technologies (e.g., } \\
\text { forums, blogs, voting systems). }\end{array}$ \\
\hline $\begin{array}{l}\text { GIS and } \\
\text { Geomatics } \\
\text { Technologies }\end{array}$ & $\begin{array}{l}\text { Provides base geographic reference } \\
\text { layers (e.g., topographic, elevation, } \\
\text { digital imagery; transportation, place } \\
\text { names); advanced analyses and } \\
\text { modeling of particular subject matter. } \\
\text { Internet-based data access and sharing } \\
\text { protocols. }\end{array}$ & $\begin{array}{l}\text { Multithematic geospatial data integration, } \\
\text { analysis, and modeling; scenarios and } \\
\text { simulations; expert systems/custom } \\
\text { analysis tools; Internet-based data access } \\
\text { and sharing protocols; some web-based } \\
\text { analysis tools. }\end{array}$ & $\begin{array}{l}\text { Web/internet-based data visualization } \\
\text { and decision-support tools; information } \\
\text { products/reports; generalized mapping } \\
\text { for nonspecialists; use of } \\
\text { cybercartography, digital atlases, and } \\
\text { 'virtual planets' (e.g., Google Earth, } \\
\text { NASA World Wind). }\end{array}$ \\
\hline
\end{tabular}

integration are identified: (1) "horizontal" integration "within" levels and (2) "vertical" integration "across" levels. The holonic tenets apply not only to integration among the three levels from bottom to top, but also to the sequence of components and processes within each level from left to right.

The sequence of questions presented in the tertiary level are a synthesis of four general stages found in many AM frameworks (Rykiel 2002, Szaro et al. 2005, Rammel et al. 2007, Hearn et al. 2008, Bizikova 2009, Bizikova and Waldick 2010). These include the following: (1) assessing current conditions, (2) exploring what might happen in the future, (3) evaluating options and deciding on a course of action, and (4) following up decisions by taking action and monitoring progress. The requirements to support tertiary-level policy and decision-making activities are identified by four corresponding decision-support capacity areas in the secondary level. It is first necessary to describe what is known about the ecosystem under question and establish baseline data integration, which will often include analyses of historical trends that lead to current conditions. This first and most fundamental step provides a necessary foundation for making predictions, i.e., forecasts and scenarios, about future possibilities. Future scenarios are then used in a risk analysis component to provide decision makers with options for consideration. The data and technologies used across these areas can be applied further in the development of indicators and monitoring systems to help track progress and evaluate the effectiveness of actions taken.

It is worth noting that in practice, the processing of information along this sequence of stages should not be expected to occur in a simple linear fashion. In reality, information flows within and between components at different rates and time periods. What this sequence indicates are the holonic dependencies that progress from left to right, in that answers (outputs) to each question (component) become necessary inputs to subsequent questions and will influence the quality of decisions and actions taken.

The holonic dependencies inherent in the primary level reflect an evolutionary sequence, left to right, from physical to biological to human systems. Because each level transcends and includes prior levels, emphasis is placed on how human systems are 
holarchically dependent on biological and physical systems (Eddy 2005, Favis-Mortlock and de Boer 2005). Positioning these three broad areas of primary scientific inquiry in this way provides the necessary elements required for comprehensive integration and synthesis on the secondary level. Ideally, scientific data and knowledge representing the human systems domain should be analyzed and structured in such a way as to allow integration with natural systems data and knowledge (Eddy and Dort 2011).

This type of integration requires geographic representations of human-natural systems interactions in space and time and presents several challenges. Integrating data and knowledge from across the full spectrum of natural and social (human) sciences requires different forms of collaboration and knowledge exchange. By emphasizing the levels of the framework as information environments, the three levels generally correspond with multidisciplinary, interdisciplinary, and transdisciplinary environments, respectively (Max-Neef 2005, Pregernig 2006). The primary level is characterized as multidisciplinary in that there are many disciplines that are often focused independently on particular subjects. Addressing complex policy issues by means of comprehensive integration across disciplines is not a priority in primary scientific research. The application of primary scientific research for addressing policy issues is the specific task of the secondary level. It is characterized as interdisciplinary in that specialists from a variety of disciplines are required to work together in a more holistic manner toward synthesis and integration. A distinctive feature of the transdisciplinary environment on the tertiary level is the need to translate highly technical language used on the primary and secondary levels into plain-language terms for which both experts and laypeople can share a common understanding. It is "trans"-disciplinary because it transcends and includes both interdisciplinary and multidisciplinary information and is neither confined nor reduced to the language used on those levels.

One of the most important aspects of these levels that characterize them as distinct information environments is related to how people collaborate and communicate with respect to the types of information with which they are working (Davenport 1997, Nardi and O'Day 2000). Each level has different challenges relating to internal organization, funding, and management support, as well as other political and cultural factors. Whereas information ecology emphasizes the central importance of these qualitative human dimensions, it does so in the context of how they coevolve with IT/IM practices. As summarized in Table 1, different forms of IT/IM are used to support the range of activities associated with the three levels, which warrants some elaboration.

\section{Information technology and management}

Information technologies that are most commonly associated with activities on the three respective levels are presented in Table 1. In general, distinctions among them pertain to the degree in which specific technologies allow users to manipulate information content. The holonic tenets apply to information content that flows from primary to tertiary levels; however, the "not vice versa" principle generally works in the opposite direction as it pertains to the level of functionality made available for manipulating information.

The technical capabilities progress from the primary to the tertiary level starting with data collection (transactional-syntactic), manipulation and analysis (analytical-semantic), to display and presentation (synthetic-pragmatic). Functionalities used on a higher level are available to lower levels, but not necessarily vice versa. Access to functionality and information content on a particular level from a higher level may be restricted for a variety of reasons related to data licensing, confidentiality, or other security restrictions or practical constraints related to types of data and functionality that users at a higher level may not normally be accustomed to using (Eddy and Taylor 2005, Pulsifer and Taylor 2005). Although it is possible to develop systems that allow users to explore options and scenarios at a tertiary level, e.g., such as in a decision-support system, the actual building of these types of systems is a technical activity that best takes place on the secondary level as part of its role in providing decision support. Secondarylevel technologies require the ability to integrate data from multiple and often disparate sources; conduct analyses and modeling, e.g. forecasts or scenarios; and further integrate these capabilities for integrated risk analysis. Data collection functionalities used on the primary level can include small-scale ubiquitous technologies for use with cell phones and laptops but more commonly pertain to large-scale systems such as satellite and airborne remote sensing systems, land survey technologies, geophysical and biophysical instruments, and technologies used in government surveys and business transactional systems.

Taken collectively, the information-handling capacities provided by the range of technologies used across the three levels are geared toward channeling the depth and span of information flow from the primary level to the tertiary level. Each level adds value to information provided from previous levels by adding depth through analysis and transformation for particular contexts. This often results in a reduction in volume of information from the lower to higher levels along individual processing streams. This reduction in volume underscores the notion that information used by decision makers merely represents the "tip of an iceberg"; one may think of the waterline as representing the boundary between the tertiary and secondary levels where the volume of information content expands, often exponentially, down to the primary level.

However, as discussed previously, because there can be multiple contexts to which the same primary information may be applied, the result is an overall heterarchical configuration of information flow similar to the relationships described in Figure 3. What gives information value in a tertiary-level environment is its concise relevance to an issue that needs to be resolved under tight time constraints. The provision of "too much information" imposes an additional information processing burden on tertiary-level users and can contribute to inefficiencies in the decision-making process. The general definition of what information is, as the complement of entropy, can be used as a guiding principle in this regard. Specialists working in a secondary-level capacity need to ensure that information products provided to tertiary-level environments are properly geared toward the context and intended use, so as to help reduce the entropy in the decision-making environment as much as possible.

Among many information technologies used across the three levels, geographic information system (GIS) and related geomatics technologies provide an invaluable means for mediating the analysis, transformation, and flow of information from the primary to the tertiary levels. Because AM requires working with 
information that deals with the interaction between human systems and natural systems, the form of information that is most amenable to capturing the complexity of this interaction in a concise, yet comprehensive manner is fundamentally geographic. Geographic location and scale are essential for establishing a proper context for the analysis and presentation of information for decision making, as well as for identifying what needs to be learned in an iterative, AM context (Taylor 1998, Eddy 2005, Grumbine 2007, Mitchell and Shrubsole 2007, O'Brien 2012). There is growing evidence showing that decision support systems that address issues related to dynamic ecological processes operating across spatial and temporal scales are more successful at both initially characterizing and assessing problems and at finding solutions that are more politically and ecologically sustainable (O'Neill 1989, Rindfuss et al. 2004, Cash et al. 2006, Greene et al. 2010, Gunderson 2010). This is because it is only through place-based analyses that the intersection of multiple drivers, pressures, and responses can be adequately contextualized (Eddy 2005, Bachtler 2010, Sadler 2010, O'Brien 2012). The use of geomatics, GIS, and related mapping technologies is of paramount importance in this respect and needs to be a core technology on each level in the framework.

\section{DISCUSSION AND FURTHER RESEARCH}

The integration of science and policy in AM is a critically important issue given that social-ecological systems are complex and our data and knowledge of them are partial and uncertain. Given that AM is essentially about "learning while doing," it is essential that policy and decision making produce the best possible use of available scientific information while respecting the cultural differences between how science is conducted and how policies and decisions are made. This is an important issue of central concern to how we approach AM, to which we have offered one approach through the development of a reference framework based on principles of information ecology. We advance this approach on the rationale that "information" needs to be a central organizing element in AM frameworks, which can enable us to think in terms of working in "information environments" that are tasked with contributing to broader socialecological adaptive processes.

Our development of the information ecology framework involved the integration of principles from diverse subjects that include information theory; ecosystem dynamics and complex, adaptive systems; holonic and holarchical theory; science-policy integration; and AM. In drawing theoretical principles from such diverse areas, it is important to recognize that we provide just some of the threads that can be synthesized toward the development of an integrated approach and advance this as a starting point for further research, development, and application. There are many other elements from each of these subject areas that may be explored in greater depth than what we have covered; however, there are a number of areas for further research that would help advance this approach further.

Whereas this initial synthesis draws from holonic/holarchy theory, further development of the framework may benefit from the incorporation of panarchy theory (Gunderson and Holling 2002). As with the panarchy model, the concept of a "holarchy" is different than that of a conventional "hierarchy," and it shares similar attributes with the panarchy model in that multiscalar and multilevel influences occur from both bottom-up and top-down interactions. Although Esbjörn-Hargens and Zimmerman (2009) make some distinctions between holarchy and panarchy, an interface between the two has yet to be fully developed. Where the panarchy model may make an important contribution is in helping to expand on some of the nonlinear dynamics of information flow both within and among levels in the framework. For example, as Holling (2004) observes, many policy issues in $\mathrm{AM}$ are driven by short time frames related to fast variables, whereas on a scientific level, there is a need to recognize the sustaining properties of slow variables operating over longer time frames. Because social-ecological problems need to be addressed over time periods that are commensurate with the rate of system change, managing the synchronicity of information flow between science and policy is an important part of the overall process. Although it is common to characterize policy and decision making as fast-paced environments and scientific research as slow paced, the reality is that the pace in either environment is influenced more by the rate of change exhibited by the components of the system under study, our scientific and technological capacity for observing and monitoring change, and our efficacy in responding to change. It is for this reason that information flows at different rates from primary to tertiary levels and between components within levels.

Closely related to the issue of information flow are the dynamic relationships among organizations whose functional roles serve different parts of the overall framework. It would be rare to find all levels and components fully present in one organization, and adopting such a framework will often require integration and collaboration among multiple organizations that can offer different areas of expertise. Some of the most important challenges relate to contrasting organizational capabilities and institutional culture (Pollard et al. 2008). An application of the panarchy model similar to that of Westley (2002) may provide insights on how to better manage information flow and coordination among organizations. For example, organizations may be at a later decision-making stage for one issue covering a particular geographic location and at an earlier decision-making stage for a different issue at the same location, or they may be at different stages of the process for the same issue, but for different geographic locations. This issue is further complicated by the fact that new scientific information will propagate from primary- to tertiary-level environments at times that may not be synchronous with management cycles. AM policy must therefore remain open to modification and refinement over time as new information is made available, and this reinforces the idea of how AM is essentially about an iterative learning process. Following this approach should lead to improved learning over time and enable human systems to be more reflexive and resilient as they coevolve with natural systems.

It would also be helpful to explore the area of disciplinarity in relation to organizational theory and institutional culture, which presents challenges for both horizontal and vertical integration within and among levels in the framework. Challenges related to horizontal integration on the primary level pertain to collaboration among different subcultures of scientists working within their respective disciplines, which are particularly discernable between the paradigms of the natural and social sciences. Such challenges are quite different from those in tertiary- 
level environments where activities and interactions among people have more to do with knowledge-power relations regarding who is involved and which policy instruments are used in relation to the scope of the system under question (Saner 2007, Smith and Stirling 2010). Although there may be an expressed desire to strive for common purposes and shared meaning at the tertiary level (Roux et al. 2006), it is more often than not an environment of "cognitive dissonance" (Bradshaw and Borchers 2000) related to competing beliefs, values, commitments, loyalties, and interests that determines what scientific information is used and what decisions and actions are ultimately taken (O'Brien 2012). It is reasonable to speculate that at least some of these challenges on the primary and tertiary levels may be addressed through secondary-level support functions, and this relates to how interdisciplinarity might function as an interface between multidisciplinary and transdisciplinary environments. As a distinctive information environment conducive to science-policy integration, one of the primary functions of the secondary level is to facilitate interdisciplinary integration on behalf of primarylevel researchers. Its role can also involve mediating conflicting values in the tertiary environment by ensuring that decisions and actions are consistent with empirical evidence, and that all values, assumptions, and uncertainties are made explicit (Hardi and Zdan 1997).

It is also worth considering research in the area of "critical theory." Diverse circumstances of societies at different times and locations contribute to a continual flux of political dynamics across multiple scales of human and natural systems interactions. Because the success of an adaptation process inherently depends on "quality" of the information used, it is also important to account for political and other social influences on "information integrity." Various genres of critical theory examine the social construction and knowledge-power influences on information flow and integrity. These may include genres that build on the works of Jacques Derrida and Michel Foucault, as well as the work of Latour (1999) in the area of science studies. Further research may also benefit from incorporating contributions from the philosophies of science and society such as those that stem from Peirce's $(1932,1933,1935,1958)$ work in semiotics and pragmatics, Popper's (1959) ideas on scientific method, or Kuhn's (1962) research on scientific paradigms.

In summary, what may be a most important contribution that this approach provides is a general model and reference framework for people to see more clearly how their respective roles contribute to a bigger picture and how important the interdependencies are for collaborating around addressing complex social-ecological issues in AM. The general relation between science and policy is made clear in the holonic tenet that stipulates how policy and decision making need to "transcend and include" science; it is a Janus-effect relationship whereby scientific information provides a foundation for good policy and decision making, while in turn, policy and decision making provide a practical context for the application of scientific information. This reinforces the message that good science is fundamental to good policy and decision making, and conversely, that contemporary social-ecological policy issues provide an important opportunity to mobilize and advance scientific research. However, effective integration between the two can only occur by giving explicit attention to the need for an intermediate level of science-policy integration and decision support.
Responses to this article can be read online at: http://www.ecologyandsociety.org/issues/responses. php/6752

\section{Acknowledgments:}

The authors acknowledge many colleagues who have supported the development of this article over the past 12 years. Thanks are given to D. R. Fraser Taylor, Ken Lawrence, Fran Klawdowsky, Simon Dalby, and Peter Pulsifer of the Department of Geography and Environmental Studies, Carleton University, for many thoughtful discussions and constructive feedback on earlier versions of this work to the first author. Sincere gratitude is also due to several colleagues with the Canadian Forest Service, Natural Resources Canada, who offered management support, encouragement, and practical suggestions: Kelvin Hirsch, Catherine Ste-Marie, Bruce Pike, and Phyllis Dale. The content of this article remains the responsibility of the authors. This article is dedicated to Jeffery Wicken and James Kay.

\section{LITERATURE CITED}

Abel, T., and J. R. Stepp. 2003. A new ecosystems ecology for anthropology. Conservation Ecology 7(3): 12. [online] URL: http://www.consecol.org/vol7/iss3/art12/

Allen, T. F. H., and T. B. Starr. 1982. Hierarchy: perspectives for ecological complexity. University of Chicago Press, Chicago, Illinois, USA.

Bachtler, J. 2010. Place-based policy and regional development in Europe. Horizons 10(4):54-58.

Baehre, R., J. E. Luther, B. Hearn, N. Novakowski, D. Piercey, D. W. Strickland, O. R. Van Lier, P. Gill, and W. Bowers. 2011. Sustainability in the Humber River Basin. International Journal of Global Warming 3(1/2):3-29. http://dx.doi.org/10.1504/ IJGW.2011.038366

Baker, K. S., and G. C. Bowker. 2007. Information ecology: open system environment for data, memories, and knowing. Journal of Intelligent Information Systems 29:127-144. http://dx.doi. org/10.1007/s10844-006-0035-7

Baskerville, G. L. 1997. Advocacy, science, policy, and life in the real world. Conservation Ecology 1(1): 9. [online] URL: http:// www.consecol.org/vol1/iss1/art9/

Bekkers, V. J. J. M., and V. M. F. Homburg. 2005. E-government as an information ecology: backgrounds and concepts. Pages 1-20 in V. J. J. M. Bekkers and V. M. F. Homburg, editors. The information ecology of e-government. IOS, Lansdale, Pennsylvania, USA.

Biggs, R., F. R. Westley, and S. R. Carpenter. 2010. Navigating the back loop: fostering social innovation and transformation in ecosystem management. Ecology and Society 15(2): 9. [online] URL: http://www.ecologyandsociety.org/vol15/iss2/art9/

Bizikova, L. 2009. Challenges and lessons learned from integrated landscape management (ILM) projects. International Institute for Sustainable Development, Winnipeg, Manitoba, Canada. 
Bizikova, L., and R. Waldick. 2010. Informing the policy process through integrated management. Horizons 10(4):81-87.

Bradshaw, G. A., and J. G. Borchers. 2000. Uncertainty as information: narrowing the science-policy gap. Conservation Ecology 4(1): 7. [online] URL: http://www.consecol.org/vol4/iss1/ $\underline{\operatorname{art} 71}$

Cantin, B. 2010. Integrated place-based approaches for sustainable development. Horizons 10(4):7-15.

Cash, D. W., W. Adger, F. Berkes, P. Garden, L. Lebel, P. Olsson, L. Pritchard, and O. Young. 2006. Scale and cross-scale dynamics: governance and information in a multilevel world. Ecology and Society 11(2): 8. [online] URL: http://www.ecologyandsociety. org/vol11/iss $2 /$ art8/

Christensen, N. L., A. M. Bartuska, J. H. Brown, S. Carpenter, C. D'Antonio, R. Francis, J. F. Franklin, J. A. MacMahon, R. F. Noss, D. J. Parsons, C. H. Peterson, M. G. Turner, and R. G. Woodmansee. 1996. The report of the Ecological Society of America committee on the scientific basis for ecosystem management. Ecological Applications 6:665-691. http://dx.doi. org/10.2307/2269460

Coren, R. L. 1998. Evolutionary trajectory: the growth of information in the history and future of earth. Gordon and Breach, Reading, UK.

Dall, S. R. X., L.-A. Giraldeau, O. Olsson, J. M. McNamara, and D. W. Stephens. 2005. Information and its use by animals in evolutionary ecology. Trends in Ecology and Evolution 20:187-193. http://dx.doi.org/10.1016/j.tree.2005.01.010

Davenport, T. H. 1997. Information ecology: mastering the information and knowledge environment. Oxford University Press, New York, New York, USA.

Dovers, S., and R. Price. 2007. Research and the integration imperative. Pages 36-55 in K. S. Hanna and D. S. Slocombe, editors. Integrated resource and environmental management: concepts and practice. Oxford University Press, Toronto, Ontario, Canada.

Eddy, B. G. 2005. Integral geography: space, place, and perspective. World Futures: the Journal of New Paradigm Research 61(1-2):151-163. http://dx.doi.org/10.1080/02604020590902434

Eddy, B. G., G. F. Bonham-Carter, and C. W. Jefferson. 2006. Mineral potential analyzed and mapped at multiple scales-a modified fuzzy logic method using digital geology. Pages 1-39 in J. Harris, editor. GIS applications in the earth sciences. Special Publication 44, Geological Association of Canada, St. John's, Newfoundland and Labrador, Canada.

Eddy, B. G., and A. Dort. 2011. Integrating socio-economic data for integrated land management (ILM): examples from the Humber River Basin, western Newfoundland. Geomatica 65 (3):283-291. http://dx.doi.org/10.5623/cig2011-044

Eddy, B. G., and D. R. F. Taylor. 2005. Exploring the concept of cybercartography using the holonic tenets of integral theory. Pages 35-60 in D. R. F. Taylor, editor. Cybercartography: theory and practice. Modern Cartography Series, Volume 4. Elsevier, Amsterdam, The Netherlands. http://dx.doi.org/10.1016/S1363-0814 (05)80006-1
Eryomin, A. L. 1998. Information ecology - a viewpoint. International Journal of Environmental Studies 54:241-253. http:// dx.doi.org/10.1080/00207239808711157

Esbjörn-Hargens, S., and M. Zimmerman. 2009. Integral ecology: uniting multiple perspectives on the natural world. Integral Books, Boston, Massachusetts, USA.

Fall, A., D. G. Morgan, and D. Daust. 2001. A framework and software tool to support collaborative landscape analysis: fitting square pegs into square holes. Transactions in GIS 5:67-86. http:// dx.doi.org/10.1111/1467-9671.00068

Favis-Mortlock, D., and D. de Boer. 2005. Simple at heart? Landscape as a self-organizing complex system. Pages 127-172 in S. Trudgill and A. Roy, editors. Contemporary meanings in physical geography. Arnold, London, UK.

Fiedler, K., A. W. Kruglanski, and E. T. Higgins. 2007. Information ecology and the explanation of social cognition and behaviour. Pages 176-200 in A. W. Kruglanski and E. T. Higgins, editors. Social psychology: handbook of basic principles. Second edition. Guilford, New York, New York, USA.

Folke, C., S. R. Carpenter, B. Walker, M. Scheffer, T. Chapin, and J. Rockström. 2010. Resilience thinking: integrating resilience, adaptability and transformability. Ecology and Society 15(4): 20. [online] URL: http://www.ecologyandsociety.org/vol15/iss4/ art20/

Gibson, R. B. 2007. Integration through sustainability assessment: emerging possibilities at the leading edge of environmental assessment. Pages 72-96 in K. S. Hanna and D. S. Slocombe, editors. Integrated resource and environmental management: concepts and practice. Oxford University Press, Toronto, Ontario, Canada.

Greene, R., J. E. Luther, R. Devillers, and B. G. Eddy 2010. An approach to GIS-based multiple criteria decision analysis that integrates exploration and evaluation phases: case study in a forest-dominated landscape. Forest Ecology and Management 260 (12):2102-2114. http://dx.doi.org/10.1016/j.foreco.2010.08.052

Grumbine, R. E. 1997. Reflections on "what is ecosystem management?" Conservation Biology 11:41-47. http://dx.doi. org/10.1046/j.1523-1739.1997.95479.x

Gunderson, L. 2010. Ecological and human community resilience in response to natural disasters. Ecology and Society 15(2): 18 [online] URL: http://www.ecologyandsociety.org/vol15/iss2/ $\underline{\operatorname{art} 18 /}$

Gunderson, L. H., and C. S. Holling. 2002. Panarchy: understanding transformations in human and natural systems. Island, Washington, D.C., USA.

Harcourt, M. 2010. From restless communities to resilient places: the role of the national government and the importance of integrated community sustainability plans. Horizons 10(4):50-53.

Hardi, P., and T. Zdan. 1997. Assessing sustainable development: principles in practice. International Institute for Sustainable Development, Winnipeg, Manitoba, Canada. [online] URL: http://www.iisd.org/pdf/bellagio.pdf 
Harris, G. 2002. Integrated assessment and modeling-science for sustainability. Pages 5-17 in R. Costanza and S. E. Jørgensen, editors. Understanding and solving environmental problems in the 21st century: toward a new, integrated hard problem science. Elsevier, Amsterdam, The Netherlands. http://dx.doi.org/10.1016/ B978-008044111-5/50003-2

Hearn, B., J. E. Luther, and D. Gray. 2008. An integrated risk analysis framework in support of sustainable forest management in Canada: project overview. Pages 38-41 in B. McAfee and C. Malouin, editors. Implementing ecosystem-based management approaches in Canada's forests: a science-policy dialogue. Natural Resources Canada, Canadian Forest Service, Ottawa, Ontario, Canada.

Hogeweg, P. 2007. From population dynamics to ecoinformatics: ecosystems as multilevel information processing systems. Ecological Informatics 2:103-111. http://dx.doi.org/10.1016/j. ecoinf.2007.01.002

Holling, C. S. 1978. Adaptive environmental assessment and management. Blackburn, Caldwell, New Jersey, USA.

Holling, C. S. 1998. Two cultures of ecology. Conservation Ecology 2(2): 4. [online] URL: http://www.consecol.org/vol2/iss2/art4/

Holling, C. S. 2004. From complex regions to complex worlds. Ecology and Society 9(1): 11. [online] URL: http://www. ecologyandsociety.org/vol9/iss1/art11/

Jones, N. A., H. Ross, T. Lynam, P. Perez, and A. Leitch. 2011. Mental models: an interdisciplinary synthesis of theory and methods. Ecology and Society 16(1): 46. [online] URL: http:// www.ecologyandsociety.org/vol16/iss1/art46/

Jørstad, E., and K. Skogen. 2010. The Norwegian Red List between science and policy. Environmental Science \& Policy 13:115-122. http://dx.doi.org/10.1016/j.envsci.2009.12.003

Jung, W. 1999. Expert advice in global environmental decision making: how close should science and policy get? Discussion Paper E-99-14, Kennedy School of Government, Harvard University, Cambridge, Massachusetts, USA.

Kappel, C. V., R. G. Martone, and J. E. Duffy. 2006. Ecosystembased management (definition). In C. J. Cleveland, editor. Encyclopedia of Earth. Environmental Information Coalition, National Council for Science and the Environment, Washington, D.C., USA. [online] URL: http://www.eoearth.org/view/ $\underline{\text { article/152249/ }}$

Kay, J. 2000. Ecosystems as self-organizing holarchic open systems: narratives and the second law of thermodynamics. Pages 135-159 in S. E. Jørgensen and F. Muller, editors. Handbook of ecosystems theories andmanagement. Lewis, Boca Raton, Florida, USA.

Koestler, A. 1967. The ghost in the machine. MacMillan, New York, New York, USA.

Kuhn, T. S. 1962. The structure of scientific revolutions. University of Chicago Press, Chicago, Illinois, USA.

Küppers, B.-O. 1990. Information and the origin of life. MIT Press, Cambridge, Massachusetts, USA.
Latour, B. 1999. Pandora's hope: essays on the reality of science studies. Harvard University Press, Cambridge, Massachusetts, USA.

Layzer, J. 2010. Ecosystem-based management in the United States. Horizons 10(4):59-63.

Lindholm, M., and T. Sarjakoski. 1994. Designing a visualization user interface. Pages 167-184 in A. M. MacEachren and D. R. F. Taylor, editors. Visualization in modern cartography. Modern Cartography Series, Volume 2. Elsevier Science, Oxford, UK. http://dx.doi.org/10.1016/B978-0-08-042415-6.50016-8

Malhotra, Y. 2002. Information ecology and knowledge management: toward knowledge ecology for hyperturbulent organizational environments. In D. L. Kiel, editor. Encyclopedia of life support systems (EOLSS). Developed under the auspices of the UNESCO, EOLSS, Oxford, UK.

Maturana, H. R., and F. J. Varela. 1980. Autopoiesis and cognition: the realization of the living. Kluwer, Dordrecht, The Netherlands. http://dx.doi.org/10.1007/978-94-009-8947-4

Max-Neef, M. A. 2005. Commentary: foundations of transdisciplinarity. Ecological Economics 53:5-16. http://dx.doi. org/10.1016/j.ecolecon.2005.01.014

McAfee, B., R. de Camino, P. Burton, B. Eddy, L. Fähser, C. Messier, M. Reed, T. Spies, and R. Vides. 2010. Managing forested landscapes for social-ecological resilience. Pages 401-435 in G. Mery, P. Katila, G. Galloway, R. I. Alfaro, M. Kanninen, M. Lobovikov, and J. Varjo, editors. Forests and society - responding to global drivers of change. International Union of Forest Research Organizations (IUFRO) World Series Volume 25, IUFRO, Vienna, Austria.

Mingers, J. 1997. The nature of information and its relationship to meaning. Pages 73-84 in R. L. Winder, S. K. Probert, and I. A. Beeson, editors. Philosophical aspects of information systems. Taylor and Francis, London, UK.

Mitchell, B., and D. Shrubsole. 2007. An overview of integration in resource and environmental management. Pages 21-35 in K. S. Hanna and D. S. Slocombe, editors. Integrated resource and environmental management: concepts and practice. Oxford University Press, Toronto, Ontario, Canada.

Nardi, B. A., and V. L. O’Day. 2000. Information ecologies: using technology with heart. MIT Press, Cambridge, Massachusetts, USA.

O'Brien, K. 2012. Global environmental change II: from adaptation to deliberate transformation. Progress in Human Geography 36(5):667-676. http://dx.doi.org/10.1177/0309132511425767

O’Neill, R. V. 1989. Perspectives in hierarchy and scale. Pages 140-176 in J. Roughgarden, R. M. May, and S. A. Levin, editors. Perspectives in ecological theory. Princeton University Press, Princeton, New Jersey, USA.

Opdam, P., R. Foppen, and C. Vos. 2001. Bridging the gap between ecology and spatial planning in landscape ecology. Landscape Ecology 16:767-779. http://dx.doi.org/10.1023/A:1014475908949 
Patten, B. C., B. D. Fath, J. S. Choi, S. Bastianoni, S. R. Borret, S. Brandt-Williams, M. Debeljak, J. Fonseca, W. E. Grant, D. Karnawati, J. C. Marques, A. Moser, F. Müller, C. Pahl-Wostl, R. Seppelt, W. H. Steinborn, and Y. M. Svirezhev. 2002. Complex adaptive hierarchical systems. Pages 41-94 in R. Costanza and S. E. Jørgensen, editors. Understanding and solving environmental problems in the 21st century: toward a new, integrated hard problem science. Elsevier, Amsterdam, The Netherlands. http://dx.doi. org/10.1016/B978-008044111-5/50005-6

Peirce, C. S. 1932. Collected papers of Charles Sanders Peirce. Volumes I and II, principles of philosophy and elements of logic. C. Hartshorne and P. Weiss, editors. Belknap, Cambridge, Massachusetts, USA.

Peirce, C. S. 1933. Collected papers of Charles Sanders Peirce. Volumes III and IV, exact logic (published papers) and the simplest mathematics. C. Hartshorne and P. Weiss, editors. Belknap, Cambridge, Massachusetts, USA.

Peirce, C. S. 1935. Collected papers of Charles Sanders Peirce. Volumes $V$ and VI, pragmatism and pragmaticism and scientific metaphysics. C. Hartshorne and P. Weiss, editors. Belknap, Cambridge, Massachusetts, USA.

Peirce, C. S. 1958. Collected papers of Charles Sanders Peirce. Volumes VII and VIII, science and philosophy and reviews, correspondence and bibliography. A. W. Burks, editor. Belknap, Cambridge, Massachusetts, USA.

Pollard, S. J. T., G. J. Davies, F. Coley, and M. Lemon. 2008. Better environmental decision making - recent progress and future trends. Science of the Total Environment 400:20-31. http://dx.doi. org/10.1016/j.scitotenv.2008.07.022

Popper, K. 1959. The logic of scientific discovery. Unwin Hyman, London, UK.

Pregernig, M. 2006. Transdisciplinarity viewed from afar: science-policy assessments as forums for the creation of transdisciplinary knowledge. Science and Public Policy $33: 445-455$.

Price, K., A. Roburn, and A. MacKinnon. 2009. Ecosystem-based management in the Great Bear Rainforest. Forest Ecology and Management 258:495-503. http://dx.doi.org/10.1016/j.foreco.2008.10.010

Pulsifer, P. L., and D. R. F. Taylor. 2005. The cartographer as mediator: cartographic representation from shared geographic information. Pages 149-179 in D. R. F. Taylor, editor. Cybercartography: theory and practice. Modern Cartography Series, Volume 4. Elsevier, Amsterdam, The Netherlands. http:// dx.doi.org/10.1016/S1363-0814(05)80010-3

Rammel, C., S. Stagl, and H. Wilfing. 2007. Managing complex adaptive systems - a co-evolutionary perspective on natural resource management. Ecological Economics 63:9-21. http://dx. doi.org/10.1016/j.ecolecon.2006.12.014

Rasmussen, J. 1999. Ecological interface design for reliable human-machine systems. International Journal of Aviation Psychology 9:203-223. http://dx.doi.org/10.1207/s15327108ijap0903 2

Rindfuss, R. R., S. J. Walsh, B. L. Turner, J. Fox, and V. Mishra. 2004. Developing a science of land change: challenges and methodological issues. Proceedings of the National Academy of
Sciences of the United States of America 101:13976-13981. http:// dx.doi.org/10.1073/pnas.0401545101

Roux, D. J., K. H. Rogers, H. C. Biggs, P. J. Ashton, and A. Sergeant. 2006. Bridging the science-management divide: moving from unidirectional knowledge transfer to knowledge interfacing and sharing. Ecology and Society 11(1): 4. [online] URL: http:// www.ecologyandsociety.org/vol11/iss1/art4/

Rowley, J. 2007. The wisdom hierarchy; representations of the DIKW hierarchy. Journal of Information Science 33:163-180. http://dx.doi.org/10.1177/0165551506070706

Rykiel, E. J. 2002. Science and decisionmaking. Pages 153-166 in R. Costanza and S. E. Jørgensen, editors. Understanding and solving environmental problems in the 21st century: toward a new, integrated hard problem science. Elsevier, Amsterdam, The Netherlands. http://dx.doi.org/10.1016/B978-008044111-5/50010$\underline{\mathrm{X}}$

Sadler, B. 2010. Spatial approaches to integrated management for sustainable development. Horizons 10(4):95-105.

Salthe, S. N. 1985. Evolving hierarchical systems. Columbia, New York, New York, USA.

Salthe, S. N. 2003. Infodynamics, a developmental framework for ecology/economics. Conservation Ecology 7(3): 3. [online] URL: http://www.consecol.org/vol7/iss3/art3/

Saner, M. A. 1999. Two cultures: not unique to ecology. Conservation Ecology 3(1): r2. [online] URL: http://www. consecol.org/vol3/iss1/resp2/

Saner, M. 2007. A map of the interface between science and policy. Council of Canadian Academies, Ottawa, Ontario, Canada. [online] URL: http://www.issp.uottawa.ca/eng/documents/ISSP2014SPIBrief6-MapoftheInterface.pdf

Sarewitz, D., and R. A. Pielke, Jr. 2007. The neglected heart of science policy: reconciling supply of and demand for science. Environmental Science \& Policy 10:5-16. http://dx.doi. org/10.1016/j.envsci.2006.10.001

Schneider, E. D., and J. J. Kay. 1994. Complexity and thermodynamics: towards a new ecology. Futures 24:626-647. http://dx.doi.org/10.1016/0016-3287(94)90034-5

Shannon, C., and W. Weaver. 1949. The mathematical theory of communication. University of Illinois Press, Urbana, Illinois, USA.

Slocombe, D. S., and K. S. Hanna. 2007. Integration in resource and environmental management. Pages 1-20 in K. S. Hanna and D. S. Slocombe, editors. Integrated resource and environmental management: concepts and practice. Oxford University Press, Toronto, Ontario, Canada.

Smith, A., and A. Stirling. 2010. The politics of social-ecological resilience and sustainable socio-technical transitions. Ecology and Society 15(1): 11. [online] URL: http://www.ecologyandsociety. org/vol15/iss1/art11/

Stepp, J. R. 1999. Prospectus for information ecology. Georgia Journal of Ecological Anthropology 3:38-54. 
Stepp, J. R., E. C. Jones, M. Pavao-Zuckerman, D. Casagrande, and R. K. Zarger. 2003. Remarkable properties of human ecosystems. Conservation Ecology 7(3): 11. [online] URL: http:// www.consecol.org/vol7/iss3/art11/

Stevens, C. J., I. Fraser, J. Mitchley, and M. B. Thomas. 2007. Making ecological science policy-relevant: issues of scale and disciplinary integration. Landscape Ecology 22:799-809. http:// dx.doi.org/10.1007/s10980-007-9092-8

Stonier, T. 1997. Information and meaning: an evolutionary perspective. Springer-Verlag, New York, New York, USA. http:// dx.doi.org/10.1007/978-1-4471-0977-8

Sturtevant, B. R., A. Fall, D. D. Kneeshaw, N. P. P. Simon, M. J. Papaik, K. Berninger, F. Doyon, D. G. Morgan, and C. Messier. 2007. A toolkit modelling approach for sustainable forest management planning: achieving balance between science and local needs. Ecology and Society 12(2): 7. [online] URL: http:// www.ecologyandsociety.org/vol12/iss2/art7/

Szaro, R. C., D. A. Boyce, Jr., and T. Puchlerz. 2005. The challenges associated with developing science-based landscape scale management plans. Landscape and Urban Planning 72:3-12. http://dx.doi.org/10.1016/j.landurbplan.2004.09.011

Taylor, D. R. F. 1998. Modern cartography, policy issues and the developing nations: rhetoric and reality. Pages $185-213$ in D. R. F. Taylor, editor. Policy issues in modern cartography. Modern Cartography Series, Volume 3. Elsevier Science, Oxford, UK. http://dx.doi.org/10.1016/S1363-0814(98)80012-9

Waldick, R. 2010. The role of institutions in integrated management. Horizons 10(4):73-80.

Westley, F. 2002. The devil in the dynamics: adaptive management on the front lines. Pages 333-360 in L. H. Gunderson and C. S. Holling, editors. Panarchy: understanding transformations in human and natural systems. Island, Washington, D.C., USA.

Wicken, J. S. 1987. Evolution, thermodynamics, and information: extending the Darwinian program. Oxford University Press, Oxford, UK.

Yaffee, S. L. 1999. Three faces of ecosystem management. Conservation Biology 13(4):713-725. http://dx.doi.org/10.1046/ j.1523-1739.1999.98127.x 